\title{
A teoria dos sistemas sociais em Niklas Luhmann
}

(Rodrigues, Leo Peixoto; Neves, Fabrício Monteiro. Niklas Luhmann: a sociedade como sistema. Porto Alegre: Edipucrs, 2012, 132 p.)

Luiz Cláudio Moreira Melo Júnior*

0 livro aborda a proposta teórica do sociólogo alemão Niklas Luhmann (19271998), considerado um dos autores mais importantes e produtivos das ciências sociais no século XX. Como Leo Rodrigues e Fabrício Neves destacam logo na introdução da obra, a abordagem teórica de Luhmann teve a ousadia de transpor "barreiras disciplinares e desenvolver um conhecimento científico verdadeiramente transdisciplinar. Tal ousadia tem se apresentado como um dos maiores empecilhos para a sua apreensão e um dos pontos preferidos de muitos de seus críticos" (p. 14). Um dos méritos do livro é apresentar de forma didática a teoria proposta por Luhmann, elucidando as principais categorias e conceitos trabalhados pelo autor e confrontando alguns dos enfoques epistemológicos centrais da teoria sociológica clássica (durkheimiana, weberiana, marxiana, estruturalista) com alguns dos fundamentos da teoria luhmanniana.

Para Leo Rodrigues e Fabrício Neves, o conceito de sistema social, tal como formulado por Luhmann, é um dos temas mais controversos das ciências sociais do século XX. Não pela sua novidade, já que outros sociólogos muito antes do autor já haviam dado centralidade ao conceito, como fez Talcott Parsons. Não obstante Luhmann seguir essa tradição, o autor apresenta uma compreensão diferente do sistema social, incorporando elementos novos na conceituação e propondo novos significados para termos antigos. Tanto é assim que o sistema teórico luhmanniano transporta para o interior das ciências sociais conceitos oriundos de diversas disciplinas científicas, tais como a biologia, a física, a psicologia, a economia, a teoria da comunicação, a cibernética, utilizando-os no estudo de fenômenos sociais. Os conceitos de autopoiésis, autorreferência, diferença sistema/entorno, operação, sentido e comunicação são alguns dos utilizados por Luhmann na sua proposta teórica.

Na teoria de Luhmann a noção de sistema é central. E é no conceito de sistema desenvolvido pelos biólogos chilenos Humberto Maturana e Francisco Varella que o autor vai se inspirar para propor uma teoria dos sistemas sociais e uma teoria da sociedade contemporânea. Para Maturana e Varella, os organismos vivos, tal como um vegetal,

\author{
* Mestre em \\ planejamento do \\ desenvolvimento \\ pelo Núcleo de Altos \\ Estudos Amazônicos \\ da Universidade \\ Federal do Pará \\ (Naea/UFPA) e \\ doutorando em \\ desenvolvimento \\ sustentável \\ pelo Centro de \\ Desenvolvimento \\ Sustentável da \\ Universidade de \\ Brasília (CDS/UnB). \\ <luiz.mmelo@ \\ hotmail.com>.
}


um animal ou uma bactéria são sistemas fechados, autorreferenciados e autopoiéticos. Isso não quer dizer que "tais sistemas são isolados, incomunicáveis, insensíveis, imutáveis, mas sim que as 'partes' ou os 'elementos' de tais sistemas interagem uns com os outros e somente entre si" (p. 24). Daí a ideia de fechamento operacional dos sistemas.

Se por um lado a noção de sistema que se generalizou na sociologia foi a concepção de sistema social aberto de Parsons, que enfatiza a troca de elementos (energia, pessoas, informação) entre os sistemas, em Luhmann encontramos uma mudança radical de perspectiva que considera, a exemplo dos organismos vivos, que os "sistemas sociais operam [...] fechados sobre sua própria base operativa, diferenciando-se de todo o resto e, portanto, criando seu próprio limite de operação" (p. 79). Ao mesmo tempo, "o fechamento é a condição da abertura do sistema ao ambiente: o sistema só é capaz de estar atento e responder à causalidade externa por meio das operações que ele próprio desenvolveu" (p. 79). As diferenças entre sistema e entorno, o fechamento operacional e a autorreferência são processos definidores dos sistemas sociais.

Os sistemas sociais são autorreferenciais porque são "capazes de operar com base em suas próprias operações constituintes" (p. 78). São autopoiéticos porque se autoreproduzem ou produzem a si mesmos enquanto unidade sistêmica. A diferenciação entre sistema e entorno, por sua vez, realça que tudo aquilo que não diz respeito ao sistema observado é tido como entorno, até mesmo "os diferentes tipos de sistemas que coexistem em uma mesma dimensão espaço-temporal" (p. 34). Com isso, o sistema social se distingue de tudo o mais, inclusive dos seres humanos. Na medida em que o sistema social e o sistema psíquico operam de forma autopoiética e de forma separada, a sociedade é tida como entorno para o indivíduo: "os seres humanos são o entorno psíquico dos sistemas sociais" (p. 81). Tal perspectiva entra em choque com toda a tradição sociológica que considera a sociedade formada por seres humanos que estabelecem relações entre si e reproduzem o que se chama de sociedade. Ainda assim, isso não significa dizer que a consciência não tenha nenhum papel para os sistemas sociais: "sistemas sociais e consciências estão em estado de interpenetração, ou seja, cada um desses sistemas é condição de possibilidade do outro" (p. 59-60).

No entanto, o que exatamente se reproduz na autopoiésis? Para Luhmann, o elemento básico de reprodução no sistema social é o processo de comunicação. Os sistemas sociais são entendidos como sistemas comunicativos. Somente a comunicação "é uma operação puramente social porque pressupõe o envolvimento de vários sistemas psíquicos sem que se possa atribuí-la exclusivamente a um ou outro destes sistemas: não pode haver comunicação individual" (p. 60-61). Dessa forma, não é o ser humano quem comunica, mas o sistema social, daí a ideia de uma comunicação e de uma "sociedade sem seres humanos". Como os autores reforçam, "a comunicação não morre 
quando alguém morre e não nasce quando alguém nasce, ela perpassa a existência de qualquer um" (p. 81). Enquanto "o sistema social existe e se reproduz como sistema de comunicação [...] os sistemas psíquicos, as consciências, reproduzem os pensamentos" (p. 59).

O conceito de comunicação ocupa, portanto, um lugar central na teoria dos sistemas sociais de Luhmann. "A comunicação é o limite da sociedade, [...] é o nó górdio a partir do qual se inicia o estudo da sociologia" (p. 55). Os autores vão além ao afirmar que o conceito luhmanniano de comunicação representa um salto epistemológico ao eliminar vários obstáculos que têm impedido uma melhor descrição dos sistemas sociais. Nessa perspectiva teórica, a comunicação é tida como uma operação mais precisa do que a ação, elemento central para a análise sociológica desde Max Weber.

Por outro lado, se à comunicação é atribuído o papel de reprodução do sistema social, o sentido é a forma dos sistemas sociais, traçando "uma linha fronteiriça entre sentido/não sentido, entre compreendido/não compreendido" (p. 47). O sentido produz o limite entre sistema e entorno, reduzindo a complexidade de ambos. O que faz sentido para o sistema social é parte de seus elementos; tudo o mais compõe o seu entorno.

A complexidade e a diferenciação social são dois outros aspectos centrais na abordagem teórica de Luhmann. A sociedade moderna é marcada por funções diferenciadas manifestas na forma de subsistemas (economia, religião, política, ciência, educação, direito). Como o sistema é sempre fechado do ponto de vista de suas operações internas, ele se diferencia de tudo mais que não seja ele próprio, definindo-se a partir de sua diferença em relação ao entorno. Uma característica dos sistemas é a redução de complexidade, dada sua função de sempre reduzir possibilidades a partir da seleção daquilo que terá sentido para o sistema quando incorporado aos processos internos. Quando atingem um elevado nível de complexidade, os sistemas produzem autonomias relativas, diferenciam-se, com o objetivo de reduzir essa complexidade. Toda diferenciação implica, portanto, redução de complexidade.

Tais processos direcionam o sistema social para a sua autorreprodução. As diferenciações que ocorreram no interior da sociedade acabaram reproduzindo funções específicas que trazem consequências para a própria evolução da sociedade. Daí a existência de "sistemas funcionais como sistemas sociais autopoiéticos diferenciados no interior do sistema social total, a sociedade. São eles economia, ciência, direito, política, religião, sistema educacional, arte, amor, movimentos sociais, entre outros" (p. 91). Nessa direção, o ponto de partida para o entendimento da dinâmica formadora dos sistemas sociais é o processo de diferenciação funcional, o que implica dizer que "a partir de si mesmo, um sistema se diferencia produzindo subsistemas parciais, 
os quais, a partir do sistema original, são agora entorno" (p. 91). Aqui reside um ponto fundamental da teoria de Luhmann: ao tempo em que os subsistemas sociais constituem entornos uns para os outros, a estrutura de relações entre eles define a própria forma como a sociedade organiza suas comunicações. E o aumento da complexidade sistêmica é o elemento que promove a diferenciação da sociedade.

Com isso, tem-se agora não a relação sistema-entorno, mas a relação sistema-sistema. Conforme os autores, o desafio consiste em "confrontar teoricamente um conceito que trate de articular autorreferencialidade sistêmica com relacionamento entre sistemas. A esta relação, entre sistemas determinados por sua própria estrutura, dá-se o nome de acoplamento estrutural" (p. 93). Ainda que os sistemas permaneçam fechados em sua própria estrutura, os "acoplamentos estruturais ocorrem corriqueiramente na sociedade moderna levando os sistemas sociais a níveis maiores de complexidade e diferenciação" (p. 94). É o que se verifica, por exemplo, no caso dos impostos (acoplamentos entre política e economia); da constituição (direito e política); dos contratos (direito e economia); das universidades (ciência e educação); das qualificações técnicas e seus certificados (educação e economia).

No último capítulo, os autores apresentam os fundamentos do positivismo funcionalista de Émile Durkheim; do método compreensivo de Max Weber; da alienação e da emancipação em Karl Marx e do estruturalismo de Claude Lévi-Strauss, para, em seguida, apresentar alguns dos aspectos que Luhmann, por meio de sua proposta sistêmica, critica e busca superar. Os autores procuram pontuar a crítica luhmanniana à teoria sociológica abordando categorias conceituais, tais como a relação sujeito/ objeto, ciência/ideologia, normatividade, ontologia e teleologia.

A crítica luhmanniana estaria centrada na necessidade de construção de um modelo explicativo da sociedade moderna que dê conta de sua atual complexidade e também no abandono de determinados pressupostos ontológicos que têm pautado grande parte dos esforços de compreensão da sociedade. Um destes pressupostos diz respeito à relação entre sujeito e objeto, discutida e problematizada nas diferentes abordagens epistemológicas - positivista, estruturalista, materialista histórica, hermenêutica, fenomenológica etc. - e que desaparece na proposta teórica de Luhmann. Nesta, não teríamos nem sujeito nem objeto, pois tanto o sujeito cognoscente (sistema psíquico) como a sociedade (sistema social) não podem comunicar-se diretamente. O sistema psíquico - que na tradição corresponde ao indivíduo, ao sujeito - é entorno do sistema social e vice-versa. Nesse sentido, "o conhecimento que o sistema psíquico consegue apreender acerca do sistema social sempre será um autoconhecimento, uma autodescrição" (p. 116-117), posto que "a sociedade como um sistema autopoiético formado por comunicações que se estabelecem recursivamente é um sistema que se autodescreve" (p. 117). 
Por fim, destaco que a leitura do livro de Leo Rodrigues e Fabrício Neves é altamente recomendável para todos os que se dedicam ao estudo das ciências sociais, iniciados ou não nos aspectos epistemológicos, teóricos e metodológicos da rica e vasta obra do sociólogo Niklas Luhmann. Não obstante, colocados os elementos, categorias e conceitos centrais da proposta teórica do autor, um grande desafio é a sua operacionalização com vistas ao desenvolvimento de novos estudos e pesquisas utilizando esse referencial teórico. Trata-se de um desafio instigante que pode produzir abordagens teórico-metodológicas inovadoras no campo das ciências sociais brasileiras e, quiçá, na interface entre ciências sociais e ciências naturais, entre sociedade e natureza. 